\title{
FAKTOR - FAKTOR YANG BERHUBUNGAN DENGAN KELUHAN LOW BACK PAIN (LBP) PADA PERAWAT DI RUMAH SAKIT X JAKARTA
}

\author{
Hardi Susanto $^{1)^{*}}$, Ajeng Tias Endarti ${ }^{1)^{*}}$ \\ Program Studi S1 Kesehatan Masyarakat Universitas MH Thamrin \\ hardypm97@gmail.com
}

\begin{abstract}
ABSTRAK
Low Back Pain (LBP) merupakan masalah kesehatan yang banyak dialami oleh tenaga kesehatan terutama perawat. LBP dapat disebabkan oleh berbagai penyakit muskuloskeletal, gangguan psikologis dan mobilisasi yang salah. Tujuan penelitian ini mengetahui faktor - faktor yang berhubungan dengan keluhan low back pain pada perawat di Rumah Sakit X Jakarta Tahun 2018. Penelitian ini merupakan penelitian kuantitatif dengan desain cross sectional. Sampel penelitian meliputi 90 perawat di RS X dengan instrumen kuesioner secara simple random sampling pada periode bulan Juni-Juli 2018. Analisis data dilakukan dengan uji chi-square. Faktor risiko yang berhubungan dengan keluhan LBP yaitu umur ( $p$ value $=0,005)$, Indeks Massa Tubuh ( $\mathrm{p}$ value $=0,007$ ). Sedangkan faktor risiko yang tidak berhubungan yaitu aktivitas berulang, jenis kelamin, kebiasaan merokok dan kesegaran jasmani. Diharapkan pada perawat untuk menyesuaikan batas kemampuan punggung sesuai usia serta memperhatikan asupan gizi makanan dan bagi pihak RS dapat memberikan fasilitas penunjang terhadap pekerja yang memiliki keluhan LBP.
\end{abstract}

Kata Kunci : Low Back Pain, Perawat, Faktor risiko.

\section{PENDAHULUAN}

Keluhan pada punggung atau keluhan musculoskeletal merupakan keluhan pada otot skeletal yang dirasakan dengan intensitas nyeri yang berbeda-beda, dari nyeri yang ringan sampai nyeri yang sangat sakit. Otot yang menerima beban statis secara berulang - ulang dan dalam waktu yang lama dapat menyebabkan keluhan berupa kerusakan pada sendi, ligament dan tendon (Tarwaka, 2004).

Berdasarkan data ILO tahun 2013, satu pekerja di dunia meninggal setiap 15 detik karena kecelakaan kerja, 160 pekerja mengalami sakit akibat kerja (Kementrian Kesehatan Republik Indonesia, 2014).

Satu survei telah melaporkan bahwa 17,3 juta orang Inggris pernah mengalami LBP. Sementara itu sekitar 26\% orang dewasa Amerika dilaporkan mengalami LBP setidaknya satu hari dalam durasi tiga bulan (NISMAT dan Bull dalam Nurbaya, 2014).

Prevalensi penyakit musculoskeletal di Indonesia berdasarkan pernah didiagnosis oleh tenaga kesehatan yaitu 11,9 persen dan berdasarkan diagnosis atau gejala yaitu 24,7 persen sedangkan (Riskesdas, 2013).

Tenaga perawat merupakan salah satu sumber daya rumah sakit yang memiliki jumlah yang cukup besar dan memiliki peranan yang sangat menentukan mutu pelayanan suatu rumah sakit. Tugas dan tanggung jawab perawat dalam melakukan asuhan keperawatan mencakup bio, psiko, sosio dan kultural terhadap kebutuhan pasien, baik itu pasien total care, partial care, maupun self care (Potter \& Perry, 2005).

Salah satu kelompok yang berisiko mengalami LBP adalah perawat. Hasil penelitian pada 3 Rumah Sakit berbeda di DKI Jakarta, terdapat tingkat risiko LBP pada perawat. Prevalensi LBP pada perawat di UGD RSUD Tarakan yaitu $61.1 \%$ kemudian prevalensi di Ruang Rawat Tahanan RS Bhayangkara yaitu 31,8\% dan prevalensi di RSS yaitu 6,25\% (Kurniawidjaja dkk, 2013). 


\section{METODE}

Penelitian ini menggunakan desain cross sectional. Populasi dalam penelitian ini adalah perawat di RS X Jakarta yang berjumlah 198 orang dan besar sampel dalam penelitian ini adalah 90 responden. Teknik pengumpulan data menggunakan data primer yaitu observasi lapangan dan kuesioner. Penyebaran kuesioner dengan simple random sampling atau secara acak sederhana. Data sekunder yaitu data yang didapatkan dari RS seperti data pekerja.

Analisis data menggunakan analisis statistik univariat untuk melihat gambaran keluhan LBP dan faktor-faktor lainya. Analisis bivariat dengan uji cox regression untuk mengetahui hubungan variabel independen dengan variabel dependen.

\section{HASIL}

1. Hasil Analisis Univariat

Dilihat pada tabel 1 diatas dapat diketahui bahwa dari 90 responden sebanyak 31 responden $(34,4 \%)$ memiliki keluhan LBP. Sementara itu mayoritas responden melakukan aktivitas tidak berulang 47 responden $(52,2 \%)$, berumur $\leq 33$ tahun sebanyak 46 responden $(51,1 \%)$, jenis kelamin peremp uan sebanyak 70 responden $(77,8 \%)$, tidak merokok sebanyak 88 responden $(97,8 \%)$, melakukan olahraga sebanyak 51 responden $(56,7 \%)$ dan memiliki IMT normal 59 responden $(65,6 \%)$.

Tabel 1

Distribusi Frekuensi Responden

\begin{tabular}{lcc}
\hline \multicolumn{1}{c}{ Variabel } & F & $\begin{array}{c}\text { Persentase } \\
(\boldsymbol{\%})\end{array}$ \\
\hline Keluhan LBP & 31 & 34.4 \\
Ada & 59 & 65.6 \\
Tidak Ada & & \\
\hline Aktivitas Berulang & 43 & 47.8 \\
Berulang & 47 & 52.2 \\
Tidak Berulang & & \\
Umur & 44 & 48.9 \\
> 33 tahun & 46 & 51.1 \\
$\leq 33$ tahun & & \\
Jenis Kelamin & 70 & 77.8 \\
Perempuan & 20 & 22.2 \\
Laki - laki & & \\
Kebiasaan Merokok & 2 & 2.2 \\
Merokok & 88 & 97.8 \\
Tidak merokok & & \\
Kesegaran Jasmani & 39 & 43.3 \\
Tidak Olahraga & 51 & 56.7 \\
Olahraga & 59 & \\
\hline IMT & & \\
Tidak Normal & & \\
Normal & & \\
\hline Sumber: Data Primer & & \\
\hline
\end{tabular}

Sumber: Data Primer 
2. Hasil Analisis Bivariat

Dilihat pada tabel 2 bahwa responden yang melakukan aktivitas berulang memiliki keluhan LBP pada 17 responden $(54,8 \%)$ dan responden yang melakukan aktivitas tidak berulang sebanyak 14 responden $(45,2 \%)$. Berdasarkan hasil uji statistik Cox Regression didapatkan p-value sebesar 0,433 artinya tidak terdapat hubungan antara aktivitas berulang dengan keluhan LBP.

Pada variabel umur dapat dilihat bahwa 22 responden (71\%) berumur $>33$ tahun memiliki keluhan LBP. Presentase ini lebih besar jika dibandingkan dengan presentase LBP pada responden berumur $\leq 33$ tahun (29\%). Hasil uji statistik Cox Regression didapatkan nilai $p=0,018$ atau $\mathrm{p}<0,05$ artinya ada hubungan antara umur dengan keluhan LBP pada perawat serta terdapat PR: 2,556; 95\% CI: 1,177-5,550 artinya responden yang berumur $>33$ tahun berisiko 2,5 kali lebih besar untuk memiliki keluhan LBP dibandingkan dengan responden berumur $\leq 33$ tahun.

Kemudian terdapat bahwa 26 responden $(83,9 \%)$ berjenis kelamin perempuan lebih besar memiliki keluhan LBP dibandingkan dengan 5 responden $(16,1 \%)$ berjenis kelamin laki-laki. Hasil uji statistik Cox Regression didapatkan $p$-value sebesar 0,418 atau $\mathrm{p}>0,05$ artinya tidak ada hubungan antara jenis kelamin dengan keluhan LBP pada perawat.

Tabel 2

Hubungan Antara Variabel Independen Dengan Keluhan LBP

\begin{tabular}{|c|c|c|c|c|c|c|c|c|c|}
\hline \multirow{3}{*}{ Variabel } & \multicolumn{4}{|c|}{ Keluhan LBP } & \multirow{2}{*}{\multicolumn{2}{|c|}{ Total }} & \multirow{3}{*}{ P-value } & \multirow{3}{*}{ PR } & \multirow{3}{*}{$95 \% \mathrm{CI}$} \\
\hline & \multicolumn{2}{|c|}{ Ada } & \multicolumn{2}{|c|}{ Tidak Ada } & & & & & \\
\hline & $\mathbf{f}$ & $\%$ & f & $\%$ & \multicolumn{2}{|c|}{ f $\%$} & & & \\
\hline \multicolumn{10}{|l|}{ Aktivitas Berulang } \\
\hline Berulang & 17 & 54,8 & 26 & 44,1 & 43 & 47,8 & 0,433 & 1,327 & $0,654-2,692$ \\
\hline Tidak Berulang & 14 & 45,2 & 33 & 55,9 & 47 & 52,2 & & & \\
\hline \multicolumn{10}{|l|}{ Umur } \\
\hline$>33$ & 22 & 71 & 22 & 37,3 & 44 & 48,9 & 0,018 & 2,556 & $1,177-5,550$ \\
\hline$\leq 33$ & 9 & 29 & 37 & 62,7 & 46 & 51,1 & & & \\
\hline \multicolumn{10}{|l|}{ Jenis Kelamin } \\
\hline Perempuan & 26 & 83,9 & 44 & 74,6 & 70 & 77,8 & 0,418 & 1,486 & $0,571-3,869$ \\
\hline Laki - laki & 5 & 16,1 & 15 & 25,4 & 20 & 22,2 & & & \\
\hline \multicolumn{10}{|l|}{ Kebiasaan Merokok } \\
\hline Merokok & 1 & 3,2 & 1 & 1,7 & 2 & 2,2 & 0,706 & 1,467 & $0,200-10,755$ \\
\hline Tidak Merokok & 30 & 96,8 & 58 & 98,3 & 88 & 97,8 & & & \\
\hline \multicolumn{10}{|l|}{ Kesegaran Jasmani } \\
\hline Tidak Olahraga & 16 & 51,6 & 23 & 39 & 39 & 43,3 & 0,354 & 1,395 & $0,690-2,821$ \\
\hline Olahraga & 15 & 48,4 & 36 & 61 & 51 & 56,7 & & & \\
\hline \multicolumn{10}{|l|}{ IMT } \\
\hline Tidak Normal & 17 & 54,8 & 14 & 23,7 & 31 & 34,4 & 0,020 & 2,311 & $1,139-4,688$ \\
\hline Normal & 14 & 45,2 & 45 & 76,3 & 59 & 65,6 & & & \\
\hline
\end{tabular}

Sumber: Data Primer

Berdasarkan tabel 2 bahwa 1 responden $(3,2 \%)$ yang merokok memiliki keluhan LBP, presentase ini lebih kecil dibandingkan dengan keluhan LBP pada responden yang tidak merokok $(96,8 \%)$ memiliki keluhan LBP. Pada uji statistik Cox Regression didapatkan nilai $p=0,706$ artinya tidak ada hubungan antara kebiasaan merokok dengan keluhan LBP pada perawat.

Berdasarkan variabel kesegaran jasmani bahwa 16 responden $(51,6 \%)$ yang tidak berolahraga memiliki keluhan LBP sedangkan 15 responden $(48,4 \%)$ yang berolahraga memiliki keluhan LBP. Dari hasil uji 
statistik Cox Regression didapatkan p-value sebesar 0,354 artinya tidak ada hubungan antara kesegaran jasmani dengan keluhan LBP pada

Berdasarkan tabel 2 dapat dilihat bahwa 17 responden (54,8\%) dengan IMT tidak normal memiliki keluhan LBP lebih besar daripada 14 responden $(45,2 \%)$ dengan IMT normal. Berdasarkan hasil uji statistik Cox Regression didapatkan $p$-value sebesar 0,020 atau $\mathrm{p}<0,05$ artinya ada hubungan antara indeks massa tubuh dengan keluhan LBP serta terdapat PR: 2,311; 95\% CI: 1,139-4,688 artinya responden dengan IMT tidak normal berisiko 2,3 kali lebih besar untuk memiliki keluhan LBP dibandingkan dengan responden dengan IMT normal.

\section{PEMBAHASAN}

\section{Aktivitas Berulang}

Aktivitas berulang adalah pekerjaan yang dilakukan secara terus menerus. Keluhan otot terjadi karena otot menerima tekanan akibat beban kerja secara terus menerus tanpa memperoleh kesempatan untuk relaksasi. Otot yang menerima beban statis secara berulang - ulang dan dalam waktu yang lama dapat menyebabkan keluhan berupa kerusakan pada sendi, ligament dan tendon (Tarwaka, 2004).

Dilihat pada hasil uji statistik Cox Regression didapatkan p-value sebesar 0,433 artinya tidak terdapat hubungan antara aktivitas berulang dengan keluhan LBP.

Hal ini disebabkan dalam pengisian kuesioner mayoritas responden menjawab pertanyaan dengan jawaban tidak lebih dari 4 pertanyaan pada lembar kuesioner serta beberapa kuesioner harus ditinggal saat penyebaran kuesioner karena kesibukan dari responden membuat peneliti tidak bisa membantu mengkontrol dalam pengisian atau ketika ada pertanyaan dari responden terkait kuesioner.

\section{Umur}

Umur akan mempengaruhi keluhan LBP yang dialami karena perubahan usia menimbulkan perubahan fisik. Secara teori, LBP mulai dirasakan pada dekade kedua kehidupan dan insiden LBP tertinggi ditemui pada dekade kelima (Tarwaka, 2004).

Menurut Betti, E et al. (1989) yang dikutip Tarwaka (2004) kekuatan maksimal otot terjadi pada saat umur antara 20 - 29 tahun, pada umur mencapai 60 tahun rata - rata kekuatan otot menurun sampai $20 \%$ dan dari faktor lain dikarenakan sikap yang tidak ergonomi mengakibatkan terjadinya LBP.

Hasil uji statistik Cox Regression didapatkan nilai $\mathrm{p}=0,018$ atau $\mathrm{p}<0,05$ artinya ada hubungan antara umur dengan keluhan LBP pada perawat serta terdapat PR: 2,556; 95\% CI: 1,177-5,550 artinya responden yang berumur >33 tahun berisiko 2,5 kali lebih besar untuk memiliki keluhan LBP dibandingkan dengan responden berumur $\leq 33$ tahun.

Hasil penelitian ini sejalan dengan Chintia (2016) bahwa pengaruh faktor-faktor risiko terhadap keluhan nyeri punggung bawah pada perawat Rumah Sakit Universitas X menunjukan ada hubungan antara umur dengan keluhan LBP pada perawat $(\mathrm{p}=0,0028<0,05)$.

Namun berbeda dari penelitian Kurniawidjaja, et all (2013) terhadap pengendalian risiko ergonomi kasus low back pain pada perawat di rumah sakit menunjukan tidak memiliki hubungan yang bermakna antara umur dengan keluhan LBP, dengan nilai $\mathrm{p}=0.634$ atau $\mathrm{p}>0.05$. 


\section{Jenis Kelamin}

Perbedaan jenis kelamin mempunyai pengaruh yang sama terhadap keluhan LBP yang dialami perawat. Menurut penelitian yang dilakukan oleh Rezaee \& Ghasemi (2014), jenis kelamin berpengaruh terhadap keluhan LBP yang dirasakan. Namun beberapa penelitian lainnya menyebutkan bahwa tidak terlalu signifikan pengaruh jenis kelamin terhadap keluhan LBP.

Berdasarkan tabel 4 dapat dilihat bahwa 26 responden $(83,9 \%)$ berjenis kelamin perempuan lebih besar memiliki keluhan LBP dibandingkan dengan 5 responden $(16,1 \%)$ berjenis kelamin laki-laki. Hasil uji statistik Cox Regression didapatkan p-value sebesar 0,418 atau p > 0,05 artinya tidak ada hubungan antara jenis kelamin dengan keluhan LBP pada perawat.

Penelitian ini sejalan dengan Patrianingrum, et al., (2015) pada perawat di Rumah Sakit X Bandung, hasil uji statistik didapatkan $\mathrm{p}$-value 0.398 ( $\mathrm{p}>0,05$ ) yang artinya tidak ada hubungan jenis kelamin dengan keluhan LBP. Hasil yang sama dilakukan Wahyuni (2016) menunjukan tidak ada pengaruh yang bermakna dari jenis kelamin dengan keluhan LBP yang dialami ( $p$-value 0,276 > 0,05).

\section{Kebiasaan Merokok}

Kebiasaan merokok akan menurunkan kapasitas paru-paru, sehingga kemampuan untuk mengkonsumsi oksigen menurun dan sebagai akibatnya tingkat kesegaran tubuh juga menurun (Tarwaka, 2004).

Berdasarkan uji statistik Cox Regression didapatkan nilai $\mathrm{p}=0,706$ artinya tidak ada hubungan antara kebiasaan merokok dengan keluhan LBP pada perawat.

Penelitian ini sejalan dengan yang dilakukan Wahyuni (2016) menunjukan tidak ada pengaruh bermakna antara kebiasaan merokok dengan keluhan LBP (p-value 0,463 > 0,05).

\section{Kesegaran Jasmani}

Tingkat keluhan otot juga sangat dipengaruhi oleh tingkat kesegaran tubuh. Laporan NIOSH yang dikutip dari hasil penelitian Cady et al. (1979) menyatakan bahwa untuk tingkat kesegaran tubuh yang rendah, maka resiko terjadinya keluhan adalah 7,1\%, tingkat kesegaran tubuh sedang adalah 3,2 \% dan tingkat kesegaran tubuh tinggi adalah $0,8 \%$ (Tarwaka, 2004).

Hasil uji statistik Cox Regression didapatkan p-value sebesar 0,354 artinya tidak ada hubungan antara kesegaran jasmani dengan keluhan LBP pada perawat.

Penelitian ini sejalan dengan yang dilakukan Kurniawidjaja (2013), uji statistik menunjukan bahwa tidak ada hubungan bermakna antara kebiasaan olahraga dengan keluhan LBP (p-value 1,00 > 0,05).

\section{Indeks Massa Tubuh}

Indeks Massa Tubuh (IMT) adalah nilai ideal massa tubuh orang dewasa yang dihitug berdasarkan berat badan dan tinggi badan dengan rumus IMT=BB $(\mathrm{kg}) / \mathrm{TB}\left(\mathrm{m}^{\wedge} 2\right)$. Kriteria nilai cut-off IMT yang digunakan di Indonesia adalah kurus $(<18,5)$, normal (18,5-25), overweight (25,1-27) dan obesitas (>27) (Depkes, 2005).

Berdasarkan tabel 7, hasil uji statistik Cox Regression didapatkan p-value sebesar 0,020 atau p < 0,05 artinya ada hubungan antara indeks massa tubuh dengan keluhan LBP serta terdapat PR: 2,311; 95\% CI: 1,139-4,688 artinya responden dengan IMT tidak normal berisiko 2,3 kali lebih besar untuk memiliki keluhan LBP dibandingkan dengan responden dengan IMT normal. 
Penelitian ini sejalan dengan Wahyuni (2016) bahwa hasil uji statistik yang di lakukan memiliki p-value $(0,011)$ $<0.05$ artinya ada hubungan pengaruh IMT dengan keluhan LBP. Namun hasil berbeda pada penelitian yang di lakukan oleh Ningsih (2017) pada perawat rawat inap Rumah Sakit X Kerinci, hasil uji statistik diperoleh nilai p $=0,132$ berarti nilai $\mathrm{p}>0,05$ maka hipotesis nol $(\mathrm{Ho})$ gagal ditolak. Dengan demikian dapat disimpulkan bahwa tidak ada hubungan signifikan antara IMT terhadap keluhan low back pain.

\section{KESIMPULAN DAN REKOMENDASI}

Hasil dari analisis univariat diperoleh gambaran bahwa dari 90 responden yang memiliki keluhan LBP sebanyak 31 responden (34.4\%). Berdasarkan analisis uji statistik chi-square ditemukan 2 variabel yang memiliki hubungan yang bermakna dengan keluhan LBP pada perawat $(\mathrm{p}<0.05)$ yaitu variabel umur ( $p$-value 0.005$)$ dan variabel IMT ( $p$-value 0.007). Sedangkan 4 variabel lainnya tidak memiliki hubungan yang bermakna dengan keluhan LBP. Bagi perawat perlu untuk mengingat batas kemampuan sesuai umur dalam melakukan pekerjaan yang memiliki beban kerja yang berat dan mengharuskan pengerahan tenaga yang berlebih serta pekerja perlu memperhatikan asupan nutrisi makanan yang cukup dan melakukan aktivitas olahraga yang rutin agar dapat menjaga kesehatan dan memiliki indeks massa tubuh yang normal. Bagi pihak RS, untuk menempatkan perawat yang memiliki umur diatas 40 tahun pada pekerjaan yang tidak memiliki beban kerja yang berat dan tidak menggunakan kekuatan tenaga yang berlebih serta membuat program penyuluhan tentang pencegahan keluhan LBP.

\section{REFERENSI}

1. Betti'e, M.C., Bigos, L.D., Fisher, T.H. 1989. Isometric Lifting strenght as a Predictor of Industrial Back Pain Report. Spine 14 (8) : 851 - 856

2. Black, J. M., \& Jacob, E. M. 2014. Medical Surgial Nursing: Clinical Management for Continuity of Care. Philadelphia: WB. Saunders.

3. Bull, E., \& Archard, G. 2007. Nyeri Punggung. Jakarta: Penerbit Erlangga.

4. Chaffin, D.B. 1979. Localized Muscle Fasique, Definition and Measurement. Journal of Occupational Medecine. $15=346-354$.

5. Chintia. 2016. Pengaruh Faktor-Faktor

6. Risiko Terhadap Keluhan Nyeri Punggung Bawah (Npb) Pada Perawat Rumah Sakit Universitas Gadjah Mada Yogyakarta tahun 2016. Tesis. Diakses pada 4 agustus 2018.

7. http://etd.repository.ugm.ac.id/index.php?mod=penelitian_detail\&sub=PenelitianDetail\&act=view\&typ $=h t m l \& b u k u \_i d=109229 \&$ obyek_id=4

8. Depkes RI, 2009. Profil kesehatan Indonesia. Jakarta: Departemen Kesehatan Republik Indonesias of body massdded

9. Depkes RI. 2005. Determining Cut-Off Point Of Body Mass Index For Obesity. Pusat Penelitian Dan Pengembangan Gizi Dan Makanan Badan Penelitian Dan Pengembangan Kesehatan Depkes, 31, 1-12

10. Grandjean, E. 1993. Fitting the task to the man, 4th ed. Taylor \& Francis Inc. London.

11. Kementrian Kesehatan Republik Indonesia. 2014. Satu Orang Pekerja Di Dunia meninggal setiap 15 detik karena kecelakaan kerja. Diperoleh tanggal 25 Mei 2018 dari http://www.depkes.go.id 
12. Kuniawidjaja. L. Meily., et al. 2013. Pengendalian Risiko Ergonomi Kasus Low Back Pain Pada Perawat Di Rumah Sakit. Jurnal MKB. 2014; 46(4):225-33.

13. Martiyas, et all,. 2015. Hubungan Aktivitas Berulang Dan Sikap Kerja Dengan Keluhan Musculoskeletal Pada Pekerja Pengangkut Sawit Di Kecamatan Rimbo Ilir Kabupaten Tebo. Jurnal Kesehatan Masyarakat. STIKES Cendekia Utama Kudus.

14. Ningsih, Kursiah W. 2017. Keluhan Low Back Pain Pada Perawat Rawat Inap Rumah Sakit X Kerinci Tahun 2017. Jurnal Ipteks Terapan, 2017: Vol:11.i1.

15. Nurbaya, S. 2014. Analisis Karakteristik Dan Klasifikasi Penyebab Nyeri Punggung Bawah Di RSUD Kota Makasar. Universitas Hasanuddin

16. Patrianingrum, Meilani. 2015, Prevalensi Dan Faktor Risiko Nyeri Punggung Bawah Di Lingkungan Kerja Anestesiologi Rumah Sakit Dr. Hasan Sadikin Bandung. Jurnal Anestesi Perioperatif. 2015;3(1): 47-56.

17. Pheasant, Stephen. 1991. Ergonomics, Work, and Health. Aspen Publisher Inc, USA

18. Potter, P. \& Perry, A. 2005. Buku Ajar Keperawatan: Konsep, Proses, Dan Praktik (Edisi 4). (Yasmin Asih et al, alih bahasa). Jakarta: EGCRazaee, M., \& Ghasemi, M. 2014.

19. Prevalence of Low Back Pain Among Nurses: Predisposing Factors and Role of Work Place Violence. Trauma Monhtly, 19(4), 9-14. http:/doi.org/10.5812/traumamon.17926

20. Riskesdas Laporan hasil Riset Kesehatan Dasar (RISKESDAS) Nasional. Badan Penelitian dan Pengembangan Kesehatan. Jakarta; 2013.

21. Santiasih, Indri. 2013. Kajian Manual Material Handling Terhadap Kejadian Low Back Pain Pada Pekerja Tekstil. J@TI Undip, Vol VIII, No 1, Januari 2013. Politeknik Perkapalan Negeri Surabaya

22. Sianturi, Mei dkk. 2015. Faktor-Faktor Yang Berhubungan Dengan Keluhan Low Back Pain (Nyeri Punggung Bawah) Pada Supir Angkot Rahayu Medan Ceria 103 Di Kota Medan Tahun 2015. Skripsi. Universitas Sumatera Utara.

23. Sopajareeya C, Viwatwongkasem C, Lapvongwatana P, Hong O, Kalampakorn S. 2009. Prevalence and risk factors of low back pain among nurses in a Thai public hospital. J Med Assoc Thai. 2009;92(Suppl 7):S93-9.

24. Suma'mur, P.K. 1982. Ergonomi untuk produktivitas kerja. Yayasan Swabhawa Karya. Jakarta.

25. Tarwaka et all, 2004, Ergonomi Untuk Keselamatan Kesehatan Kerja dan Produktivitas, Surakarta: UNIBA press.

26. Tarwaka. 2015. Ergonomi Industri Dasar-Dasar Pengetahuan Ergonomi dan Aplikasi di Tempat Kerja. Surakarta: Harapan Press.

27. Tjokorda G.B. Mahadewa dan Sri Maliawan. 2009. Diagnosis dan Tatalaksana Kegawat Daruratan Tulang Belakang, Jakarta: CV Sagung Seto.

28. Wahyuni, Fia. 2016. Analisis Faktor-Faktor Risiko Yang Mempengaruhi Keluhan Low Back Pain (LBP) Pada Perawat. Tesis. Universitas Indonesia. 
29. Waters, T.S. \& Putz-Anderson, V. 1996. Manual materials handling. Edited by Bharattacharya, A \& McGlothlin, J.D. 1996. Occupational Ergonomics Theory and Applications. Marcel Dekker Inc. New York. 329-350.

30. Yanra, E. P. 2013. Gambaran penderita LBP di poliklinik bedah RSUD Raden Matther Jambi. Universitas Jambi. 